\title{
System approach to using information modelling technology in sustainable construction production development
}

\author{
Ruben Kazaryan*, Denis Pogodin, Praskovia Andreeva, Natalia Galaeva and Elena \\ Tregubova \\ Moscow State University of Civil Engineering, 129337, Moscow, Russia
}

\begin{abstract}
The paper considers the possibility of studying the potential for the effectiveness of the economic and visual model and reducing operating costs in the development of construction facilities. Methods of visual modelling are presented, which make it possible to effectively implement construction organization projects. The economic and visual model contributes to the formation of the element base of rational economic, organizational and technological solutions. The following methods were used: system analysis, logical-mathematical modelling, systems theory, economic and visual modelling, research methods of operations, economic and mathematical methods. The modern experience of using the model has been studied. On the basis of an analytical review regarding economic and visual modelling, the works of domestic and foreign authors are studied. The element base of the optimal solution of organizational and technological processes is formed on the basis of the information model (BIM). The conducted analytical review of the study of materials on the practical application of the economic and visual model on the territory of the Russian Federation based on the results of the theoretical study confirms that there is no alternative to improving the formation of new information systems for modelling the organization of
\end{abstract}

\section{Introduction}

In the conditions of risk and uncertainty, there is a need for continuous management of economic processes in the public sector. Changes of the last decades have shifted the focus financial and managerial accounting from cost management and financial flows onto economic processes' management (financial standing, risks, backup enterprise system, reorganization processes, value added control ), based on the use of accounting engineering tools (monitoring, financial, hedging, or other derivative reports). The net assets indicator, in conjunction with net liabilities, represents one of the most important measures of assessing economic processes, efficiency, and sustainable development of a nonprofit enterprise. However, as concerns businesses that are not focused on profit-making or satisfaction of public demand for services as the outcome of investment, this indicator is

${ }^{*}$ Corresponding author: r.kazarian@mail.ru 
difficult to determine. Therefore, a lot of proven models and methods of accounting for net assets cannot be directly applied in this area. This situation leads to a mismatch between the urgent need for scientific methodology in the field of information and analytical support of management and evaluation of the efficiency by using the net assets indicator [15-17]. As a result, it becomes necessary to introduce certain methodologies and additional tools that will make it possible to design in three-dimensional space not the object itself, but its construction process in time. In other words, the design process from this point on is not static, but dynamic. This technique is a completely new method in architectural and construction design. The concept of economic and visual modelling of the construction process is a new and progressive approach to the development of organizational and technological solutions and the identification of spatial and temporal collisions, which in turn leads to a reduction in construction time and minimization of unplanned budget expenditures [1-11].

\section{Efficiency criteria and restrictions}

Construction companies set themselves tasks, the solution of which will make it possible to effectively implement construction projects. The solution of the assigned tasks is possible due to well-developed organizational and technological solutions. An obligatory criterion is the possession of deep and extensive knowledge of the object under construction [2-3]. At present, during the construction of objects, software systems are widely introduced into the design process, which make it possible to model the object being built in three-dimensional space (3D). These software systems allow further automation of receiving layout drawings. Each correction that is made to the model is automatically modified in the corresponding drawings. This method significantly improves the quality of products produced by the personnel, organizational and technological solutions become well-developed, which in turn minimizes the likelihood of collisions in the area of joining spatial models. With the help of automation and visualization, the probability of spatial inconsistencies is reduced to 98\% [1-3]. The advantages of three-dimensional modelling are reflected at all stages of the construction of an object, while the development of 3D models at present can cost significantly more than the well-known classical two-dimensional drawings. However, the improvement in the formation of new information systems for modelling the organization of construction objects, subject to the introduction of appropriate adjustments and changes in the organizational and technological processes, will reduce the cost of ongoing design work by $5-10 \%$ [4-5]. For the effective implementation of projects, time-tested methods are used:

1. The activity progress chart (APC) of a project is a process model that reflects the sequence and dependence of work performance. APC allows calculating the most favourable way in terms of time parameters, which allows effective performance of the most complex works. APC is mainly used in the construction of particularly complex and large facilities with a large number of construction and installation works. The critical path method is used in the design of APC.

2. The critical path method makes it possible to estimate the amount of full, private and free time reserve that is available in each work. Work that is not included in the critical path can be carried out in stages - as appropriate, or even begin later, since it does not affect the total duration of the construction of the facility. The critical path method allows setting the optimal time for completion of the construction of a facility for a given budget.

3. The flow line method of organizing construction work is a rational organization of labour. A mandatory element in using the flow line method is to minimize downtime and maximize resource utilization. 
The above methods have some limitations. For example, APC may contain a large number of errors related to the one-time use of space at a construction site (different works in the schedule are independent). This kind of situation at a construction site creates certain time costs of individual teams due to the impossibility of starting the performance of the previous or subsequent work [3-5]. Synergy is achieved with the simultaneous use of the above methods, when organizational and technological decisions are made on the basis of a visual model. The model is often referred to as 4D-, 5D-, 6D-, MULTI-D- modelling. Multidimensional modelling combines a three-dimensional model of an object under construction, 3D and APC [6-7]. The economic and visual model (computer), which allows the interconnection of construction processes presented in three-dimensional space with reference to time, makes it possible to make rational organizational and technological decisions in the design of construction organization project (COP), work performance project (WPP), project of organization of work (POW), clearly argue them for the developer, technical customer, general contractor and all participants in the process. APC does not provide an opportunity to consider the adopted organizational and technological decision visually in the space of the coordinate system $(\mathrm{X}, \mathrm{Y}, \mathrm{Z})$. This fact creates certain difficulties in considering it. The development of computers makes it possible to consider the adopted organizational and technological decisions with reference to the $3 \mathrm{D}$ model of an object, taking into account information about the equipment and the cost of certain types of work [6-8], while the computer may contain information about the labour force, the materials used at certain stages of the construction, cost rates, multiple elements of economic visualization coefficients [12-17]. Figure 1 shows a facility under construction using a computer. It should be noted that when creating a scale model that ensures the functioning of the economic and visual model, extended integration into the CAD system is required, based on the element base of BIM standards (figure 2).

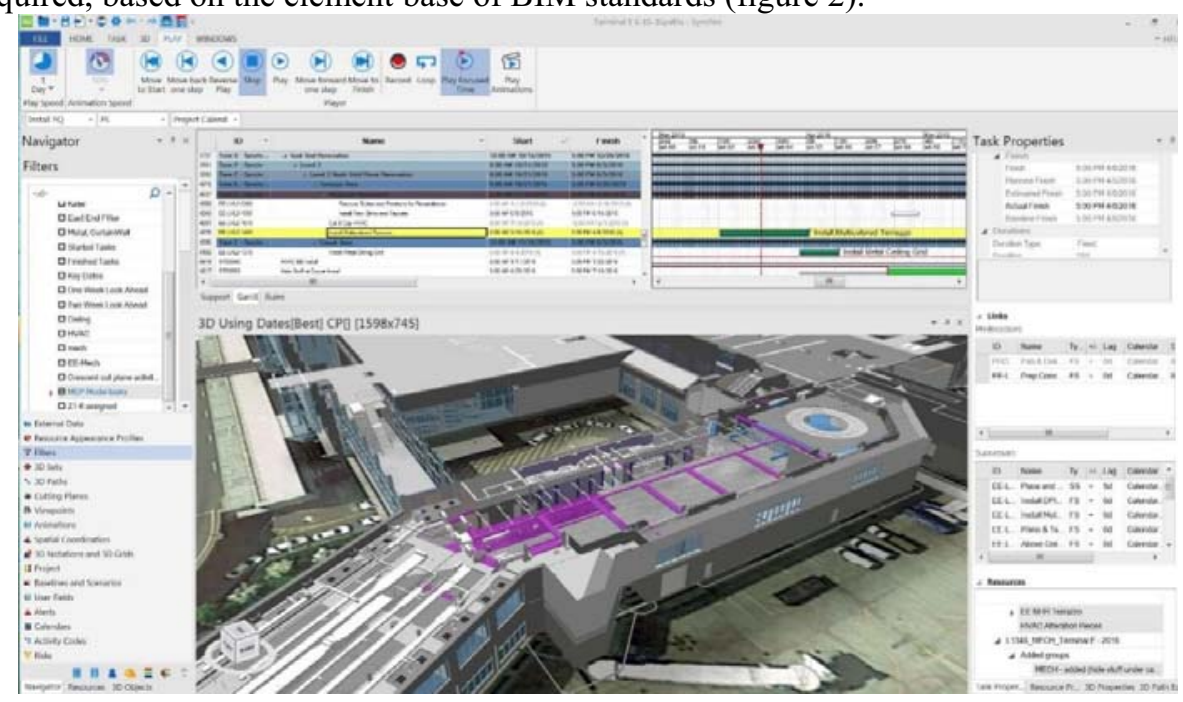

Fig. 1. An illustrative example of a visual model of a facility under construction 


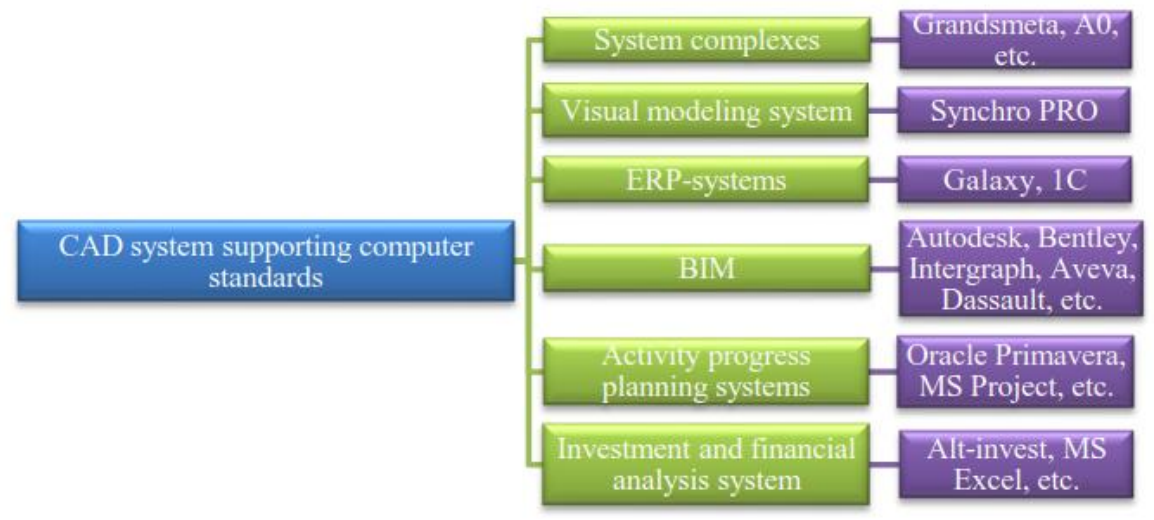

Fig.2. CAD systems supporting computer standards

In addition to the above tasks, the computer allows calculating and correct flaws in the APC, establishing the most rational terms, taking into account the arrangement of construction equipment, schemes for the provision of equipment and materials, visual analytics for comparing organizational and technological solutions, search and elimination of spatial, temporal and space-time collisions[17]. Figure 3 shows the methodology for the development of information models in order to eliminate inconsistencies: project risks in the design of COP, WPP, POW, and space-time collisions[7-9,15-17].

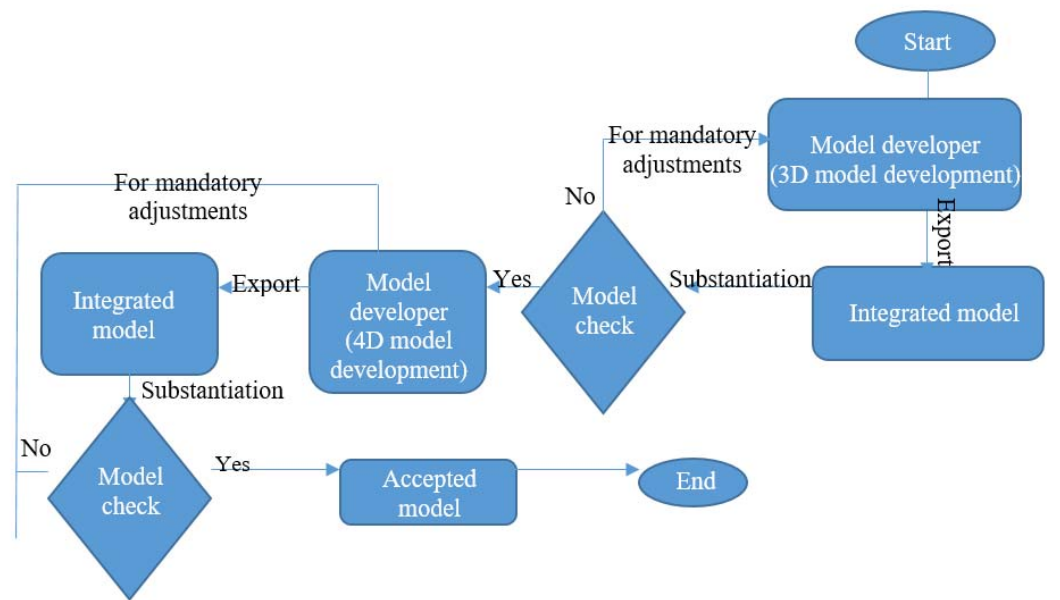

Fig. 3. Method for the development and validation of 4D and 5D models.

\section{Results and discussions}

The first stage of the construction of a facility, which determines the future characteristics of buildings and structures, is the design process. At this stage, the issues of functional purpose, durability, architectural expressiveness, operational qualities of the object and so on are solved. For the effective implementation of the project, a rational approach to making organizational and technological decisions is required, the development of which is carried out within the framework of the construction organization project (COP). It is 
important to note that today it is impossible to build objects of increased complexity without introducing computer aided design systems (CAD) into the design process. The functional purpose of CAD is increasing every year, since it gets close attention of designers and software developers. As a result of progressively developing information modelling systems, the designers were faced with the need to develop organizational and technological solutions in a single information field. This approach is not possible when using traditional design methods in three-dimensional space. Economic and visual modelling as a tool for effectively implementing construction projects on the territory of the Russian Federation has not been widely used for certain reasons. At present, experience has been accumulated in the use of computers in the preparation of design estimates for some companies.

Distinctive features include:

- lack of generation of economic benefits as the main goal of activities;

- predominance of a non-market way of organizing activities;

- production, distribution, and consumption of public goods;

- lack/restriction of the ownership right to property and other resources administered by a non-profit institution, which are publicly owned and controlled by the state authorities;

- ensuring an economic equilibrium between demand and supply of public goods through state mechanisms (social institutions, infrastructure, and resources);

- the ability, within acceptable limits, to carry out activities aimed at deriving additional economic benefit while maintaining the objective functions of the public goods distribution and achievement of goals of the state in meeting social needs. One of such projects is the object of using atomic energy in the city of Dimitrovgrad (developer - JSC "SSC RIAR"). A computer element base was formed for it. The introduction of computers in the development of COP provided an opportunity to identify and eliminate design flaws. The results obtained in the process of testing the computer at this facility are presented in table 1 $[11-15,17]$.

Table 1.Results of applying the economic and visual model

\begin{tabular}{lll} 
Characteristics of the tested object & Base values & Values of computer testing \\
\hline Duration of construction, including: & 55 months & 50 months \\
- preparation period & 5 months & 6 months \\
- foundation pit & 4 months & 4 months \\
- construction of a reactor block & 46 months & 40 months \\
excluding the foundation pit & & \\
Construction cost & 10.04 billion roubles & 8.37 billion roubles \\
\hline
\end{tabular}

Based on the results of the adjustments made to the design documentation, it was possible to reduce the construction time, the deadline for the construction of the reactor block, and the total cost of the construction.

As a result of the analytical study, the main provisions regarding the development of project documentation using the economic and visual model were identified:

- A computer can provide the ability to make rational organizational and technological decisions in the design of COP, WPP, POW;

- A computer can provide the ability to analyze the adopted organizational and technical decision visually in space in the coordinate system $(\mathrm{X}, \mathrm{Y}, \mathrm{Z})$;

- A computer can provide the ability to assess the adopted organizational and technological solutions with reference to the $3 \mathrm{D}$ model of an object, taking into account information about the equipment and the cost of certain types of work; 
- A computer can provide the ability to generate information about labor resources, materials used at certain stages of construction, cost prices, numerous elements of the economic visualization coefficients [12-16].

\section{Conclusions}

1. A computer is a progressive method for the development of construction management projects. The methodology contains a specific algorithm that allows using appropriate tools to effectively implement construction projects.

2. A computer has certain disadvantages. The main disadvantage is the costly restructuring of companies (the need for a position - a system manager to manage and coordinate processes in a single environment in the CAD system, partial replacement of working personnel for the effective implementation of projects in the CAD system, loss of personnel for a very significant period of time)

3. The greatest effect when using a computer is achieved when designing standard facilities. The efficiency of using computers in the construction of unique facilities is currently economically inexpedient

4. Russian construction companies are taking their first steps. There is an experience in designing nuclear power facilities, civil engineering, oil and gas facilities. In western countries, computers were introduced much earlier. Data provided by McGraw-Hill Construction shows that in 2007, 26\% of general contractors used computers, and in 2012 $71 \%$.

5. Design with the use of economic and visual modelling makes it possible to improve the quality of decisions based on modelling development options with an assessment of their cost and time characteristics, to solve problems of assessing the coefficients of economic visualization that are optimal in terms of the efficiency of using the element base in the interests of the developer, when implementing organizational and technological solutions for the construction project of the facility

6 . The net assets are formed as an increase of economic benefits arising in the operation process, of the result of changes in the value of assets. However, disputable remains the question of recognition of value of the investments of the owner directly in the composition of net assets, which may be seized without the consent of the institution at the time of liquidation of the organization or other cases stipulated by the law.However, as noted above, the obligation arises only in relation to a physical object in the volume and condition of wear on the liquidation date. The amounts of accumulated depreciation and residual value of this object does not, in our opinion, reflect the true assessment of the property. As depreciation, although they may be correlated with a tendency of loss of physical and moral characteristics by the object in some cases, as a whole, are predominantly a tool to compare the income and expenses of the organization and the resulting residual value cannot give a reliable valuation of the asset at the current date.

\section{References}

1 S.Bachurina and I. Sultanova, Urban Planning 1(35), 11-14 (2015)

2 S .Bachurina and I. Sultanova, Actual problems of socio-economic development of Russia 4, 67-70 (2014)

3 H. McGraw, Construction The Business Value of BIM in North America: Multi-Year Trend Analysis and User Ratings (2007-2012) Smart Market Report (2012) www.construction.com 
4 A. Lapidus et al., System engineering in construction, Cyber-Physical Building Systems, 331-334 (2019)

5 V. Talapov, PLM Electronic Encyclopedia (2010) http://isicad.ru/ru/ 97

6 E. Kolosova E. and K. Sukhachev, Atomic strategy 54 (2011)

7 V. Grachev et al., STI Organization and methodology of information work 5, 18-22 (2006)

8 A. Balakina et al., E3S Web of Conf. 33, 03044 (2018)

9 C. Boton et al., Proceedings of the 15th International Conference Information Visualisation (IV), UK, London, (2011)

10 I. Sultanova, Methodology for the development of projects for the organization of construction on the basis of the economic and visual mode 1 (2015)

11 R. Kazaryan et al., E3S Web Conf. 157, 04009 (2020)

12 R. Kazaryan et al., E3S Web Conf. 157, 04006 (2020)

13 R. Kazaryan, and P. Andreeva, IOP Conference Series: Materials Science and Engineering 753, 042038 (2020)

14 V. Chulkov and R. Kazaryan, Advances in Economics, Business and Management Research 138, 371-376

15 V. Chulkov et al., Journal of mechanics of continua and mathematical sciences Special issue 8, 144-154(2020)

16 T. Simankina, et al., Advances in Intelligent Systems and Computing 983, 138-145, (2019) https://doi.org/10.1007/978-3-030-19868-8_13

17 R. Kazaryan et al., Construction Techniques Bulletin (BST) 7, 44-45 (2018) 